\title{
NETNOGRAPHIC STUDY ABOUT NEWBORN CARE: BLOGGER MOMS AND DADS IN TURKEY
}

Selmin Şenol*, Canan Sümeyra Gün**

${ }^{* * *}$ Ege University Faculty of Nursing Department of Pediatric Health and Diseases, Izmir, Turkey ** Msc, Izmir, Turkey

\section{Aim}

Newborn is in a struggle for adapting itself to the life in the neonatal process. Parents are responsible for the primary care of the newborn. They have to do many things such as ensuring security environment and providing quality care. This process leads them to do research from several resource and to learn. The aim of this study is to define issues and views which are handled by the blogger parents who talk about newborn care on the internet environment in Turkey.

\section{Methodology}

This research is a descriptive study which has been conducted through netnographic method(1). Parents blogs that were detected via the keywords "newborn care, blog, parents" on the search engine were examined through netnographic method. The topics handled on the blogs were evaluated in the light of the literature.

Result

Ten mothers' and three fathers' blog were detected as a result of the research. It was found out that parents had a university education and career when the blogger profiles were examined. There are; "breastfeeding"," sleep ","colic","umbilical cord falls","diaper dermatitis","stuffed nose", newborn hepatitis", "kangaroo care", "circumcision", "lactose intolerance", "bath", "hip dislocation" and "supplies that are needed by newborns" among the topics which are handled by parents. These are shown in figure 1.

Topics such as breastfeeding hours, storage conditions of breast milk and the amount of the breast milk sucked by the newborn have been handled when it comes to feeding the newborn. They have handled issues like drawbacks from holding the newborn and points to be considered when parents change newborn's diaper and give it a bath. Sleep duration of the newborn is another topic that has been handled most. Colic, umbilical cord falls and care are other issues that have been highlighted. Materials which are needed for the newborn have been mentioned and brands in this respect have been recommended apart from the health topics related to the care of the newborn. However, mothers have not made any explanation for medical information on these recommendations.

1. Kozinetz RV. Netnography: Doing ethnographic research online. Sage publications, 2010. 2. Dhillon, A. S., Albersheim, S. G., Alsaad, S., Pargass, N. S., \& Zupancic, J. A. (2003). Internet use and perceptions of information reliability by parents in a neonatal intensive care unit. Journal f Perinatology, 23(5), 420.

Jang, J., \& Dworkin, J. (2012). Babycenter. com: New parent behavior in an online

community. In The Forum for Family and Consumer Issues (Vol. 17).

4. DeLuca, J. M., Kearney, M. H., Norton, S. A., \& Arnold, G. L. (2012). Internet use by parents of infants with positive newborn screens. Journal of inherited metabolic Disease, 35(5), 879-884. 5. Plantin, L., \& Daneback, K. (2009). Parenthood, information and support on the internet. A literature review of research on parents and professionals online. BMC family practice, 10(1), 34 6 . Niela-Vilén, H., Axelin, A., Salanterä, S., \& Melender, H. L. (2014). Internet-based peer support for parents: A systematic integrative review. International Journal of Nursing Studies,

\section{Discussion}

Today, quick access to the information via the internet leads individuals, groups and the society to the fields such as websites, e-mail and blog within the seek for information related to health (2). It was seen that bloggers writing via the internet often remain faithful to the time and they write regularly. The majority of the group in the sample stated that they are educated and they have a career on their blogs. The studies which were conducted show that the parents who search for information and share information on the internet are generally educated and have a career $(3,4)$. In addition that parents search for information, they have a tendency to learn what other parents do like themselves. They share how they have coped with and what they have done as well as they convey their experiences and provide peer support. Studies which were conducted in previous years also emphasize peer support in this respect $(5,6)$. However, this study has not included an explanation of the source of medical information in the shared information and experiences as in the previous studies. The gap in this respect points out that the sources of information related to neonatal health should be safer.

As a result, transfer of similar descriptive studies into more detailed experimental studies will provide the gaps in this regard to show up clearer. The new findings will shed light on how health professionals and especially pediatric nurses should maintain a stance with regard to sources of information on the internet.

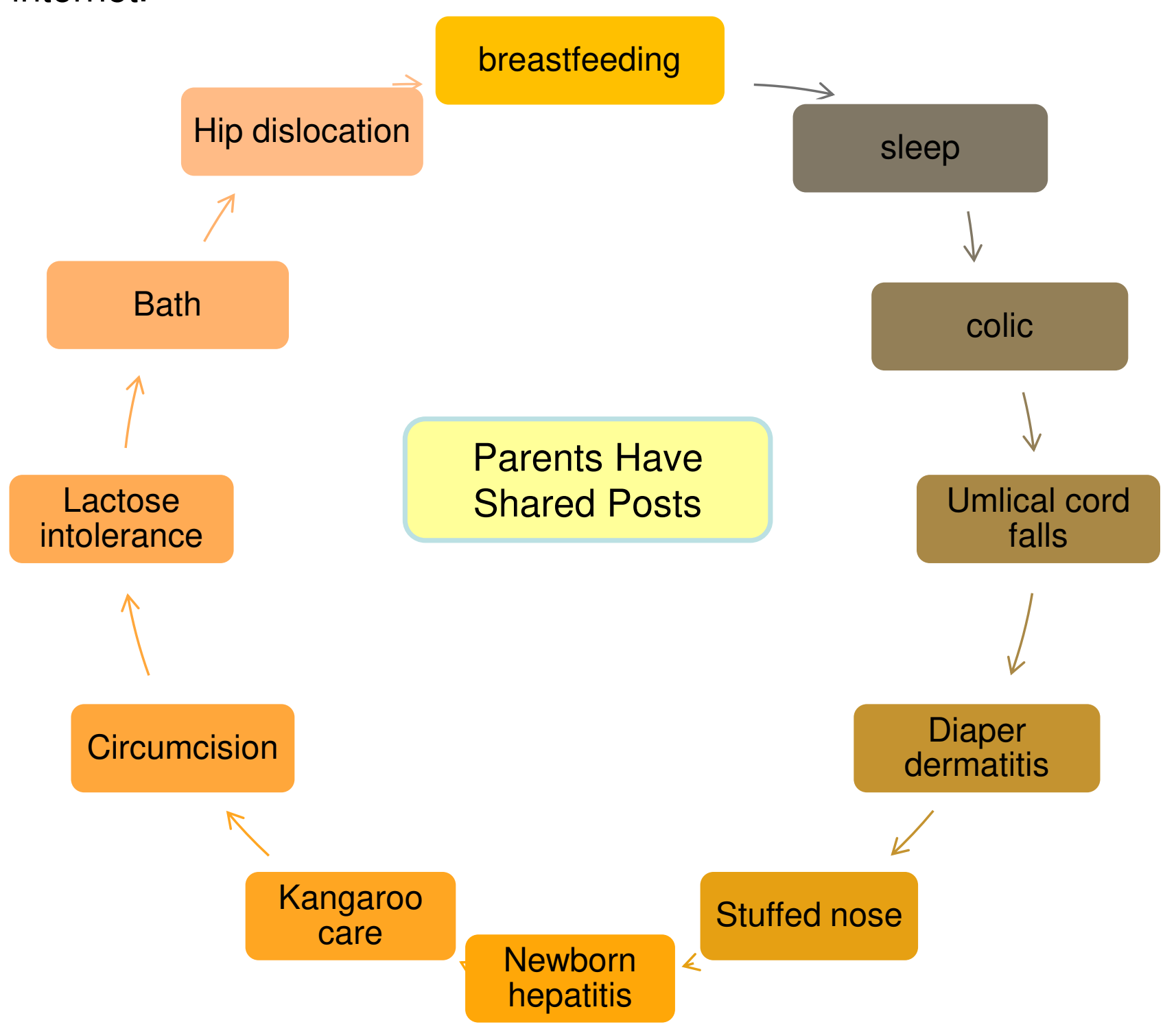

Figure 1:Parents Have Shared Posts 